\title{
Nanostructured fluids for the removal of graffiti - A survey on 17 commercial spray-can paints
}

\author{
Michele Baglioni ${ }^{\mathrm{a}, 1}$, Giovanna Poggi ${ }^{\mathrm{a}}$, Yareli Jaidar Benavides ${ }^{\mathrm{b}}$, \\ Fernanda Martínez Camacho ${ }^{c}$, Rodorico Giorgi ${ }^{\mathrm{a}, *}$, Piero Baglioni ${ }^{\mathrm{a}, 1}$ \\ a Department of Chemistry and CSGI, University of Florence, via della Lastruccia, 3, 50019 Sesto Fiorentino (FI), Italy \\ ${ }^{\mathrm{b}}$ The Institute of Aesthetic Research of the National Autonomous University of Mexico Calle Mario de La Cueva S/N, Coyoacán, Cd. Universitaria, 04510 \\ Ciudad de México, CDMX, Mexico \\ ${ }^{\mathrm{c}}$ Instituto Nacional de Antropología e Historia-Centro INAH Oaxaca, José María Pino Suárez 715, Centro, 68000 Oaxaca, Mexico
}

\section{A R T I C L E I N F O}

\section{Article history:}

Received 7 February 2018

Accepted 18 April 2018

Available online 18 June 2018

\section{Keywords:}

Graffiti

Cleaning

Alkyd

Nanostructured fluids

Surfactants

Spray-can paints

\begin{abstract}
A B S T R A C T
Graffiti removal from monuments, such as statues or architecture, is becoming a priority for conservators and restorers. This operation is further complicated when the vandalism is carried out on surfaces that should be preserved, as in the case of writings or tags on historical wall paintings, or even on modern or contemporary pieces of street art. Several methods exist for graffiti removal, which include chemical, physical or biological approaches. However, traditional methodologies, such as the use of neat organic solvents, are often unsuitable. Moreover, due to the great variability of brands and formulation of commercial paints, a thorough study of materials used for graffiti and a deep knowledge of their behavior when exposed to cleaning media is currently lacking. In this contribution, we report a systematic laboratory survey on 17 different spray-can paints available on the market and commonly used for graffiti and vandalism in the Mexican area. These paints were analyzed by means of ATR FT-IR spectroscopy to characterize their composition. Several solvents, having different nature and polarity, were then used to remove the paints from glass slides. On the basis of these results, two different amphiphile-based nanostructured fluids, which present several advantages with respect to traditional cleaning methodologies, were formulated and tested on the same paint samples. Finally, the two nanostructured cleaning systems were used for the removal of vandalistic graffiti from stones decorated with red pre-Hispanic paintings in the archeological site of Ba' Cuana, Asunciòn Ixtalpetec, Oaxaca, Mexico.
\end{abstract}

(c) 2018 Elsevier Masson SAS. All rights reserved.

\section{Research aims}

The removal of graffiti is becoming a priority for conservators and restorers. However, traditional cleaning methods, such as the use of unconfined organic solvents, are often unsuitable. Moreover, conservators have to deal with a huge variety of commercial paints commonly used for graffiti and a systematic study on their properties is currently missing. In this paper, a systematic laboratory survey on 17 different spray-can paints available on the market and commonly used for graffiti and vandalism in the Mexican area is presented and discussed. These paints were analyzed by means of physical techniques and their removability using different solvents was tested. According to these tests, two innovative

\footnotetext{
* Corresponding author.

E-mail address: giorgi@csgi.unifi.it (R. Giorgi).

${ }^{1}$ No kinship exists among these authors.
}

water-based cleaning media were proposed and tested on the same paints, which represent a significant improvement with respect to traditional cleaning methodologies, in terms of eco-compatibility, toxicity and control. Finally, the two new cleaning systems were used for the removal of vandalistic graffiti from archeological conserved in Ba' Cuana, Asunciòn Ixtalpetec, Oaxaca, Mexico.

\section{Introduction}

Graffiti can be found in most urban contexts, all over the world. Even if tags, writings and drawings, usually made with spray-can paints, often represent the expression of an underground subculture and in some cases can be considered as a non-conventional form of art expression, graffiti are mainly regarded as a criminal practice, since their execution is usually related to public and private violations, with damaging of buildings or monuments. In these cases, graffiti are carried out without any artistic intention, during protests, demonstrations, marches, public events, etc. In fact, 
graffiti are a growing threat for the conservation of works of art and architecture easily accessed by the public. It is not unlikely that monuments, such as statues, art installations or facades of historic buildings become jeopardized and vandalized through the application of several kinds of commercial paints.

For instance, given the political and social situation of Mexico, the National Institute of Anthropology and History (INAH) has had to deal with the removal of numerous graffiti and vandalisms from several archaeological and historical buildings. The choice of the cleaning methodology to be used mainly depends on two factors: the media used (spray-paint, felt pen or enamel paints) and the type of material that has been vandalized (e.g. stone, stucco, wood or metal, having different porosities and surface properties). Graffiti removal is further complicated when the vandalism is carried out on a surface to be preserved, as in the case of writings and tags executed on historical wall paintings, or even on modern or contemporary pieces of street art (often made with similar or the same materials as the vandalism) [1].

For all these reasons, starting from the 1990s, conservators and conservation scientists have been searching for solutions and methodologies to safely and selectively remove graffiti from buildings and monuments [2-10], and for anti-graffiti products [11-14], designed to prevent the adhesion of paint layers to surfaces of artistic interest. Current methodologies for the removal of graffiti can be ideally grouped in three classes: chemical, physical and biological methods [4]. Chemical cleaning is the most used among the procedures for graffiti removal [4]. In fact, several organic solvents can swell, soften or solubilize the paints used for graffiti, which are usually based on synthetic polymers, such as alkyd, acrylic or vinyl, as binding media. Physical methods, on the other hand, include the use of scalpels, abrasive media, pressurized water blasting or sandblasting $[4,8,15]$, other than more innovative techniques, i.e., laser ablation, ultrasonic agitation, plasma spray, arc or thermal spray, dry ice-blasting and soda blasting [4,7-10,15-20]. Finally, biological methods, proposed at the end of 1990s, generally involve the use of living microorganisms to remove undesired materials through biodegradation [21-24]. However, even if chemical cleaning may result effective in graffiti removal, the use of neat unconfined organic solvents is often unsuitable in this context. In fact, their cleaning action is scarcely selective, poorly controllable and it may cause dissolving of the paint and its spreading into the porosity of the substrate. Therefore, conservation scientists have been lately searching for innovative methodologies, inspired by soft-matter chemistry, as an effective alternative to the use of traditional cleaning procedures.

This paper aims to demonstrate the efficacy of water-based systems for the removal of synthetic paint layers. Tests executed using neat solvents allowed to identify the best candidates to be used for the formulation of amphiphile-based nanostructured fluids (NSFs).

NSFs, such as micellar solutions and microemulsions, have been proposed since the early 1990s for the removal of synthetic polymers from porous inorganic substrates like wall paintings or stones [25-31]. These cleaning media are generally composed of water, surfactant(s) and one or more organic solvents, and present several advantages with respect to the use of neat unconfined organic solvents. First of all, toxicity and environmental impact of the cleaning systems are significantly decreased. In fact, NSFs used in conservation of cultural heritage are aqueous-based and the amount of organic solvents is usually reduced to 5-35\%. Finally, and most important, when NSFs are used, the paint layer to be removed is not actually solubilized (as it would happen using neat unconfined organic solvents); it is rather swollen and softened [32,33], sometimes through a dewetting process [34]. Therefore, it has to be subsequently removed by means of a careful and soft mechanical action using a cotton swab or a (rubber or metal) scalpel. This is why the spreading of dissolved paint in the pores of the substrate is avoided and the removal action is much more controlled and selective with respect to traditional methodologies.

The choice of the most effective cleaning NSF for the removal of a given graffiti is not straightforward. Several variables and factors are at play, i.e., the chemical nature of the paint used for graffiti, its ageing, the chemical nature, surface morphology and porosity of the substrate from which graffiti have to be removed and, finally, whether the vandalism was executed on a painting that has to be preserved or not. In every country several brands of spray-can paints can be found on the market and conservators dealing with graffiti removal must know as much as possible about the properties of these materials. To the best of our knowledge, a thorough investigation on the chemical nature, composition and removal of the materials employed for graffiti is still missing.

In this contribution, we report a systematic laboratory survey on 17 different spray-can paints available on the market and commonly used for graffiti and vandalism in the Mexican area. These paints were analyzed by means of ATR FT-IR analyses in order to clarify their composition.

According to the needs of Mexican conservators, two different water-based NSFs were developed and used for the removal of vandalistic graffiti from stones decorated with red pre-Hispanic paintings in the archeological site of Ba' Cuana, Asunciòn Ixtalpetec, Oaxaca, Mexico.

\section{Materials and methods}

\subsection{Chemicals}

Sodium dodecylsulfate (SDS, Sigma-Aldrich, purity $\geq 99 \%$ ), $\mathrm{C}_{9-11} \mathrm{E}_{6}$ ethoxylated alcohol (Stepan, assay E95\%), acetone (Ac, Carlo Erba s.p.a., purity >99\%), 2-butanone (MEK, Sigma-Aldrich, purity 99\%), ethanol (EtOH, Carlo Erba s.p.a., purity $>98.5 \%$ ), 2-propanol (2-PrOH, Sigma-Aldrich, purity >98\%), 2-butanol (2$\mathrm{BuOH}$, Sigma-Aldrich, purity $>99.5 \%$ ), 1-pentanol $(\mathrm{PeOH}, \mathrm{Merck}$, purity $\geq 98.5 \%$ ), ethyl acetate (EA, Sigma-Aldrich, ACS reagents, purity $\geq 99.5 \%$ ), butyl acetate (BuA, Sigma-Aldrich, purity $>99 \%$ ), diethyl carbonate (DeC; Sigma-Aldrich, purity 99\%), dibutyl carbonate (DbC; Massimo Guarducci s.r.l., purity $>98.5 \%$ ), propylene carbonate (PC, Sigma-Aldrich, purity 99\%), p-xylene (Xyl, Merck, purity $>99.5 \%$ ), nonane (Non, Sigma-Aldrich, purity $>99 \%$ ) were used as received, without further purification. Water was purified with a Millipore Milli-Q gradient system (resistance $>18 \mathrm{M} \Omega \mathrm{cm}$ ).

\subsection{Spray-can paints}

The 17 spray-can paints were purchased from the companies “360" (Mexico), "Montana” (Spain) and "Illegal Squad” (Mexico) and used as received. More detailed information on the paints are reported in Table 1 . The choice was based on giving a significant overview on the main colors and paint brands used for graffiti in the Mexico City area.

\subsection{NSFs preparation}

The NSFs were prepared adding each component under constant stirring, until an optically clear system was obtained. Firstly, the surfactant was dissolved in water, so as to obtain a micellar solution. Then the co-surfactant, i.e. $\mathrm{PeOH}$ or $2-\mathrm{BuOH}$, was added to this system, in order to modify the micelles' interface. Finally, the organic solvents were added dropwise to these ternary systems until the final formulation was reached. Their composition was previously developed through the study of a significant portion of their pseudo-ternary phase diagram. The composition of the two systems (\% w/w) is as follows: (NSF A) water $73.3 \%$, SDS $3.7 \%$, 
Table 1

Information about the selected spray-can paints, including commercial name, supplier and diluent, as indicated in the technical sheets (if available).

\begin{tabular}{|c|c|c|c|c|c|}
\hline Sample & Paint name & Supplier & Color & Diluent & Binder \\
\hline 1 & $\begin{array}{l}\text { Malbec } \\
(\mathrm{RE} / 115)\end{array}$ & $360(\mathrm{MX})$ & Dark pink & - & - \\
\hline 2 & $\begin{array}{l}\text { Bean brown } \\
\text { (RV98-MNT94) }\end{array}$ & Montana (ES) & Coffee & Aromatic mixture & Alkyd \\
\hline 3 & $\begin{array}{l}\text { Dioxazine purple light } \\
\text { (RV214-water-based 300/100) }\end{array}$ & Montana (ES) & Violet & $\mathrm{H}_{2} \mathrm{O} /$ alcohol & Modified polyurethane \\
\hline 4 & $\begin{array}{l}\text { Flamingo } \\
\text { (RV259-hardcore) }\end{array}$ & Montana (ES) & Light pink & Aromatic mixture & Alkyd \\
\hline 5 & $\begin{array}{l}\text { Quinacridone rose } \\
\text { (RV211-water-based 300/100) }\end{array}$ & Montana (ES) & Love pink & $\mathrm{H}_{2} \mathrm{O} /$ alcohol & Modified polyurethane \\
\hline 6 & Violeta Vampiro & Ilegal Squad (MX) & Light violet & - & - \\
\hline 7 & $\begin{array}{l}\text { Naphthol red } \\
\text { (RV3020-water-based 300/100) }\end{array}$ & Montana (ES) & Light red & $\mathrm{H}_{2} \mathrm{O} /$ alcohol & Modified polyurethane \\
\hline 8 & Azul Mahahual & Ilegal Squad (MX) & Dark blue & - & - \\
\hline 9 & Naranja jaguar & Ilegal Squad (MX) & Orange & - & - \\
\hline 10 & $\begin{array}{l}\text { Azo orange light } \\
\text { (RV2004-water-based 300/100) }\end{array}$ & Montana (ES) & Light orange & $\mathrm{H}_{2} \mathrm{O} /$ alcohol & Modified polyurethane \\
\hline 11 & Rojo Sacrificio & Ilegal Squad (MX) & Red & - & - \\
\hline 12 & Amarillo Medio & Ilegal Squad (MX) & Yellow & - & - \\
\hline 13 & Magenta & Ilegal Squad (MX) & Pink & - & - \\
\hline 14 & Blanco Brillante & Ilegal Squad (MX) & White & - & - \\
\hline 15 & Azul Cielo & Ilegal Squad (MX) & Sky blue & - & - \\
\hline 16 & Azul Profundo & Ilegal Squad (MX) & Dark blue & - & - \\
\hline 17 & Verde Lima & Ilegal Squad (MX) & Lime green & - & - \\
\hline
\end{tabular}

PeOH 7\%, EA 8\%, PC 8\%; (NSF B) water 60\%, $\mathrm{C}_{9-11} \mathrm{E}_{6}$ 5\%, 2-BuOH $10 \%$, PC 7\%, MEK 11\%, EA 7\%.

\subsection{Spray-can paint samples preparation}

The paint samples were prepared by spraying a homogeneous layer of paint on top of $5 \mathrm{~cm} \times 5 \mathrm{~cm}$ frosted glass slides. The samples were then kept at room temperature and common indoor illumination for one year before cleaning tests were carried out, in order to let set the paint.

\subsection{ATR FT-IR spectroscopy}

ATR measurements were carried out with a Thermo Nicolet Nexus 870 spectrometer equipped with a liquid nitrogen-cooled HgCdTe detector and a single reflection diamond crystal ATR unit. Spectra were recorded in the $4000-650 \mathrm{~cm}^{-1}$ range (128 scans, $2 \mathrm{~cm}^{-1}$ resolution). ATR measurements were performed on small samples of spray-can paints' dried films, removed from the glass support.

\subsection{Laboratory and in situ cleaning tests}

Laboratory cleaning tests with neat organic solvents and NSFs were performed using cotton swabs soaked with the cleaning liquids. Cotton swabs were gently rolled on the surface of the paint for a few seconds in order to test the response of the coating to the cleaning mechanical action. Pictures of the samples and the cotton swabs were carefully taken during all the tests. The result of each cleaning test was then evaluated and assigned to one of the following five categories:

- easy solubilization/swelling and removal;

- solubilization/swelling and removal with some mechanical action;

- partial swelling and removal with significant mechanical action;

- partial swelling and poor removal;

- no removal.

In order to get clearer and semi-quantitative results, a score going from 4 to 0 were given to each one of the aforementioned categories, being 4 top removal and 0 no removal. In situ cleaning tests were also performed by means of cotton swabs soaked with the NSFs and used to perform some mechanical action on the graffiti to be removed. The results were carefully documented by taking pictures of all the tests executed. Further tests were performed on larger areas by means of cellulose pulp poultices loaded with the NSFs, applied on Japanese paper sheets and covered with plastic films to prevent the evaporation of the liquid.

\section{Results and discussion}

\subsection{Characterization of the spray-can paints}

In the present study, 17 spray-can paints commonly used for graffiti in the Mexican area were selected. As indicated in Table 1, these systems are from three different suppliers and differ in colors. Information about diluents and binders, reported in the last two columns of the same table, where obtained from the technical sheets, available only in the case of paints supplied by Montana. Four of Montana paints are reported to be based on modified polyurethane and diluted in a water/alcohol mixture, while the remaining two paints are said to be alkyd-based and diluted in an unknown aromatic mixture.

The characterization of the selected spray-can paints was conducted on dried films using ATR FT-IR spectroscopy. Spectra of paints are usually complicated, since the signals from binder, pigment, dyes, extenders and other additives are often overlapped. The results obtained, including the chemical nature of binder, fillers and pigments or dyes are summarized in Table 2.

The selected paints can be classified based on the type of binder, assigned using ATR spectra. In the case of paints 2 and 4, both from Montana, the presence of an alkyd binder reported in the technical sheet was confirmed by ATR measurements (the spectrum of sample number 2 is reported in Fig. 1). Peaks at $2928 \mathrm{~cm}^{-1}$, and $2855 \mathrm{~cm}^{-1}$ are due to the asymmetric and symmetric stretching of $-\mathrm{CH}_{2}-$ and $\mathrm{CH}_{3}$, while $\mathrm{CH}$ bending and $\mathrm{CO}$ carbonyl stretching are found at about $1460 \mathrm{~cm}^{-1}$ and $1720 \mathrm{~cm}^{-1}$, respectively. In the fingerprint region, peaks attributed to $\mathrm{C}-\mathrm{O}$ stretching can be seen at $1257 \mathrm{~cm}^{-1}$ and $1067 \mathrm{~cm}^{-1}$, while the peak at $1386 \mathrm{~cm}^{-1}$ is due to the symmetric in-plane bending of $\mathrm{CH}$ [35-37]. 
Table 2

Composition of the selected spray-can paints, including binders, extenders and pigments, obtained from ATR measurements.

\begin{tabular}{|c|c|c|c|c|c|c|}
\hline \multirow[t]{2}{*}{ Sample } & \multirow[t]{2}{*}{ Paint name } & \multicolumn{3}{|l|}{ Binder } & \multirow[t]{2}{*}{ Extender } & \multirow[t]{2}{*}{ Pigment } \\
\hline & & Polyurethane & Alkyd & Alkyd-Styrene & & \\
\hline 1 & Malbec & - & - & $\mathrm{x}$ & - & Azo dye \\
\hline 2 & Bean Brown & - & $\mathrm{x}$ & - & - & Azo dye \\
\hline 3 & Dioxazine Purple Light & $\mathrm{x}$ & - & - & $\mathrm{T}$ & $?$ \\
\hline 4 & Flamingo & - & $\mathrm{x}$ & - & - & $?$ \\
\hline 5 & Quinacridone Rose & $\mathrm{x}$ & - & - & $\mathrm{T}$ & Quinacridone \\
\hline 6 & Violeta Vampiro & - & - & $\mathrm{x}$ & K & Azo dye \\
\hline 7 & Naphtol Red & $\mathrm{x}$ & - & - & - & Naphthol red \\
\hline 8 & Azul Mahahual & - & - & $\mathrm{x}$ & K & $\mathrm{Cu}$-phthalocyanine \\
\hline 9 & Naranja Jaguar & - & - & $\mathrm{x}$ & K & Chrome yellow \\
\hline 10 & Azo Orange Light & $\mathrm{x}$ & - & - & $\mathrm{T}$ & Azo dye \\
\hline 11 & Rojo Sacrificio & - & - & $\mathrm{x}$ & K & Azo dye \\
\hline 12 & Amarillo Medio & - & - & $\mathrm{x}$ & - & Chrome yellow \\
\hline 13 & Magenta & - & - & $\mathrm{x}$ & K & $?$ \\
\hline 14 & Blanco Brillante & - & - & $\mathrm{x}$ & K & Titanium white \\
\hline 15 & Azul Cielo & - & - & $\mathrm{x}$ & K & Prussian blue \\
\hline 16 & Azul Profundo & - & - & $\mathrm{x}$ & $\mathrm{K}$ & Prussian blue \\
\hline 17 & Verde Lima & - & - & $\mathrm{x}$ & $\mathrm{K}$ & Cu-phthalocyanine \\
\hline
\end{tabular}

$\mathrm{T}=$ talc; $\mathrm{K}=$ kaolinite. Where "?" is present in the last column, it was not possible identifying the pigment or, more likely, dye present in the paint.

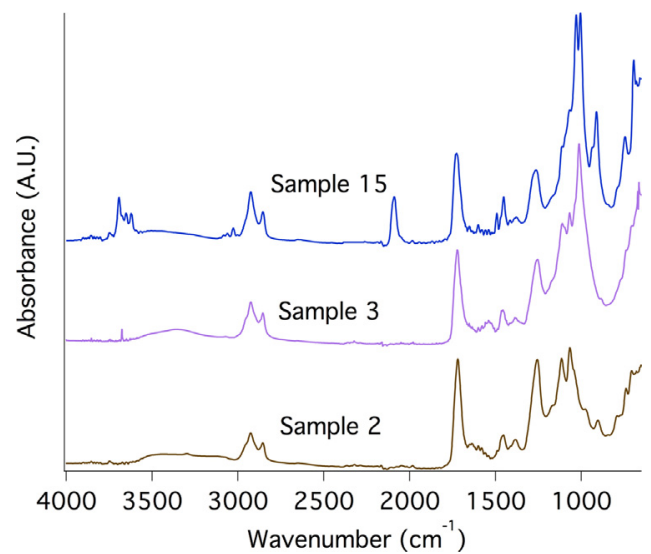

Fig. 1. Comparison between spray-can paints having different binders: alkyd (sample 2), polyurethane (sample 3 ) and alkyd-styrene (sample 15). Peaks due to two types of extenders, namely talc and kaolinite, can also be seen (sample 15 and sample 3 , respectively).

Eleven paints, ten from Illegal Squad and one from 360, were found to be based on an alkyd-styrene binder. The ATR spectrum of one of these paints, i.e., sample number 15, is reported in Fig. 1. In addition to the peaks belonging to alkyds, indicated above, these paints show peaks at about $3000 \mathrm{~cm}^{-1}$ due to the $\mathrm{CH}$ stretching of the aromatic rings, as well as the $\mathrm{C}=\mathrm{C}$ stretching peak at around $1600 \mathrm{~cm}^{-1}$. In the fingerprint region, the out-of-plane deformation peaks are found at 740 and $707 \mathrm{~cm}^{-1}$ [35-37].

As reported in the technical sheets, polyurethane is the binder of sample 3, whose ATR spectrum can be seen in Fig. 1, and of samples 5, 7 and 10, all from Montana. The binder is probably formed by reacting di- or polyisocyanates with polyols. In fact, in the ATR spectrum, several peaks due to polyols, also typical of alkyd resins, can be found. The presence of the urethane group can be assessed by several peaks, such as the one at $1541 \mathrm{~cm}^{-1}$ due to the coupling of $\mathrm{N}-\mathrm{H}$ bending vibration with $\mathrm{C}-\mathrm{N}$ stretching vibration in the $-\mathrm{C}-\mathrm{NH}$ group (amide II band), which can be seen in Fig. 1 sample 3 [35,38,39].

Extenders, or fillers, are inorganic minerals whose refractive index approximately is equal to that of the binder. Therefore, they have very little scattering power. These are added to the paints to replace polymer or pigment volume so to reduce the cost of raw material [40]. For what concerns the selected spray-can paints, four samples, having a polyurethane binder (Montana), contain

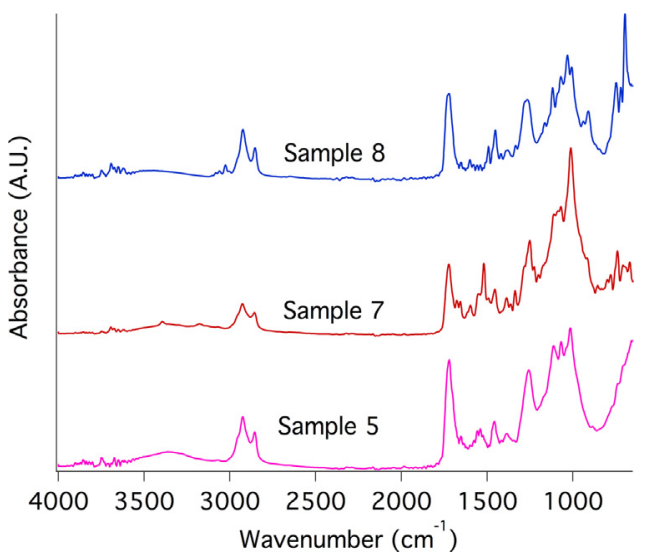

Fig. 2. Comparison between spray-can paints having different organic pigments: quinacridone (sample 5), naphthol red (sample 7) and $\mathrm{Cu}$-phthalocyanine (sample 8).

talc, a clay mineral composed of hydrated magnesium silicate. Its presence is assessed by peaks at $3675 \mathrm{~cm}^{-1}, 1013 \mathrm{~cm}^{-1}$ and $665 \mathrm{~cm}^{-1}$, as can be seen from Fig. 1 - sample 3 [41]. On the other hand, in several samples from Illegal Squad, peaks due to the presence of kaolinite, another clay mineral with the chemical composition $\mathrm{Al}_{2} \mathrm{Si}_{2} \mathrm{O}_{5}(\mathrm{OH})_{4}$, are clearly visible. In particular, three strong peaks related to the stretching of $\mathrm{OH}$ groups are found at about $3690-3610 \mathrm{~cm}^{-1}$, while, in the fingerprint region, several signals at $1114 \mathrm{~cm}^{-1}, 1024 \mathrm{~cm}^{-1}, 1003 \mathrm{~cm}^{-1}, 911 \mathrm{~cm}^{-1}, 749 \mathrm{~cm}^{-1}$ and $696 \mathrm{~cm}^{-1}$ are present, as can be seen in the spectrum of sample 15 , in Fig. 1 [41].

The color of paints is due to the presence of inorganic or organic pigments and dyes. Inorganic pigments are finely grinded colored minerals. Organic pigments, or dyes, on the other hand, are carbocyclic, ring-containing (usually) synthetic molecules having several aromatic conjugations. A third class of pigments/dyes is represented by organometallic compounds, where metal ions are bound to or complexed by organic molecules. As one would expect, ATR FT-IR spectra of organic and organometallic pigments are much more complicated that the ones of inorganic pigments. For what concerns the selected spray-can paints, five samples $(9,12,14$, $15,16)$ contain inorganic pigments. In the case of two blue paints, samples 15 (Fig. 1) and 16, the presence of Prussian Blue, Iron(III) hexacyanoferrate(II), was assessed by the strong peak at about $2087 \mathrm{~cm}^{-1}$, which is due to the vibration of the cyanide group [42]. 
Table 3

Cleaning tests with neat organic solvents.

\begin{tabular}{|c|c|c|c|c|c|c|c|c|c|c|c|c|}
\hline \multirow[t]{2}{*}{ Paint name } & \multicolumn{2}{|c|}{ Ketons } & \multicolumn{3}{|c|}{ Alcohols } & \multicolumn{2}{|c|}{ Esters } & \multicolumn{3}{|c|}{ Alkyl carbonates } & \multirow{2}{*}{$\begin{array}{l}\text { Aromatics } \\
\text { Xyl }\end{array}$} & \multirow{2}{*}{$\begin{array}{l}\text { Alkanes } \\
\text { Non }\end{array}$} \\
\hline & Ac & MEK & EtOH & $\mathrm{PrOH}$ & $\mathrm{PeOH}$ & EA & $\mathrm{BuA}$ & $\mathrm{DeC}$ & $\mathrm{DbC}$ & PC & & \\
\hline Malbec & 4 & 4 & 1 & 1 & 1 & 4 & 4 & 3 & 3 & 1 & 4 & 1 \\
\hline Bean brown & 3 & 3 & 1 & 1 & 1 & 3 & 1 & 1 & 1 & 1 & 3 & 0 \\
\hline Dioxazine purple light & 3 & 3 & 3 & 3 & 1 & 2 & 1 & 1 & 1 & 0 & 3 & 0 \\
\hline Flamingo & 3 & 3 & 3 & 2 & 1 & 3 & 3 & 3 & 1 & 1 & 1 & 0 \\
\hline Quinacridone rose & 3 & 1 & 2 & 2 & 1 & 1 & 1 & 1 & 1 & 1 & 3 & 1 \\
\hline Violeta Vampiro & 4 & 4 & 4 & 3 & 1 & 4 & 4 & 3 & 3 & 3 & 4 & 0 \\
\hline Naphtol Red & 3 & 2 & 3 & 3 & 1 & 3 & 1 & 3 & 3 & 1 & 2 & 0 \\
\hline Azul Mahahual & 4 & 3 & 2 & 2 & 2 & 3 & 3 & 3 & 2 & 2 & 3 & 1 \\
\hline Naranja jaguar & 2 & 2 & 2 & 1 & 2 & 2 & 1 & 3 & 3 & 1 & 3 & 0 \\
\hline Azo orange light & 2 & 3 & 2 & 1 & 1 & 3 & 1 & 1 & 1 & 1 & 3 & 0 \\
\hline Rojo Sacrificio & 4 & 4 & 1 & 1 & 1 & 1 & 3 & 3 & 2 & 1 & 1 & 0 \\
\hline Amarillo Medio & 3 & 3 & 1 & 1 & 3 & 2 & 1 & 1 & 2 & 0 & 2 & 0 \\
\hline Magenta & 4 & 4 & 3 & 3 & 1 & 4 & 3 & 4 & 3 & 0 & 3 & 0 \\
\hline Blanco Brillante & 2 & 1 & 0 & 0 & 1 & 1 & 1 & 2 & 0 & 0 & 1 & 0 \\
\hline Azul Cielo & 3 & 3 & 2 & 2 & 1 & 3 & 3 & 3 & 3 & 1 & 3 & 1 \\
\hline Azul Profundo & 2 & 2 & 1 & 1 & 1 & 2 & 2 & 2 & 2 & 1 & 2 & 1 \\
\hline Verde Lima & 2 & 1 & 1 & 1 & 1 & 1 & 3 & 2 & 1 & 1 & 2 & 1 \\
\hline Average result & 3.00 & 2.71 & 1.88 & 1.65 & 1.24 & 2.47 & 2.12 & 2.29 & 1.88 & 0.94 & 2.53 & 0.35 \\
\hline
\end{tabular}

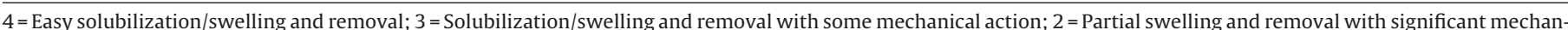
ical action; 1 = Partial swelling and poor removal; $0=$ No removal. Water was tested but not reported because it was ineffective on all the selected spray-can paints.

The third blue paint (sample 8), whose spectrum is reported in Fig. 2, on the other hand, contains an organometallic pigment, probably a copper phthalocyanine. Phthalocyanines are indeed the most diffuse blue and green synthetic organic pigments. The presence of Cu-phthalocyanine, detected also in sample 17, is assessed by the peak at about $1500 \mathrm{~cm}^{-1}$ due to aromatic groups vibrations, as well as by the signals at $748 \mathrm{~cm}^{-1}$ and $723 \mathrm{~cm}^{-1}[41]$.

In Fig. 2 are also reported the ATR spectra of two red-violet paints (sample 5 and 7). These paints, both from Montana, are based on polyurethane binders and organic pigments. The pigment of sample 5 belongs to the family of quinacridones, a class of lightfast red and violet pigments used for industrial coatings and artist's paints. Naphthol red is the pigment of sample 7; these red and orange pigments are characterized by a $\beta$-naphthol ring substituted with both an aromatic azo and an aromatic amide [43].

\subsection{Laboratory cleaning tests with neat solvents}

For laboratory cleaning tests with neat solvents, ketones, alcohols, esters, alkyl carbonates, aromatic hydrocarbons and alkanes were selected. The cleaning tests were carried out performing a gentle mechanical action with cotton swabs, as reported in section 3.6. In order to make the discussion of the results clearer, a score ranging from 0 (no removal) to 4 (optimum removal) was assigned to each cleaning test and the complete set of results is reported in Table 3. The assignment of this score has been done on the basis of empirical subjective evaluations and, thus, it has to be regarded as a rough parameter, which should help the readers in following the discussion of results and data.

By looking at Table 3, the removal of the paints from the glass support was achieved in all the cases, with, at least, one or more of the selected solvents and, in some spare cases, with an intense mechanical action. Interestingly, no correlation seems to exist between the chemical nature of the paint polymeric binder and its easiness of removal. In fact, in some cases, paints containing the same binder behave very differently when exposed to the cleaning action of the same solvent. This is clearly visible, for instance, in the case of samples 13 and 14, Magenta and Blanco Brillante, both based on an alkyd-styrene binder, which gave completely different results when treated with acetone or MEK. Sample 13 was easily removed with both solvents, while sample 14 could be removed only with some tough mechanical action.

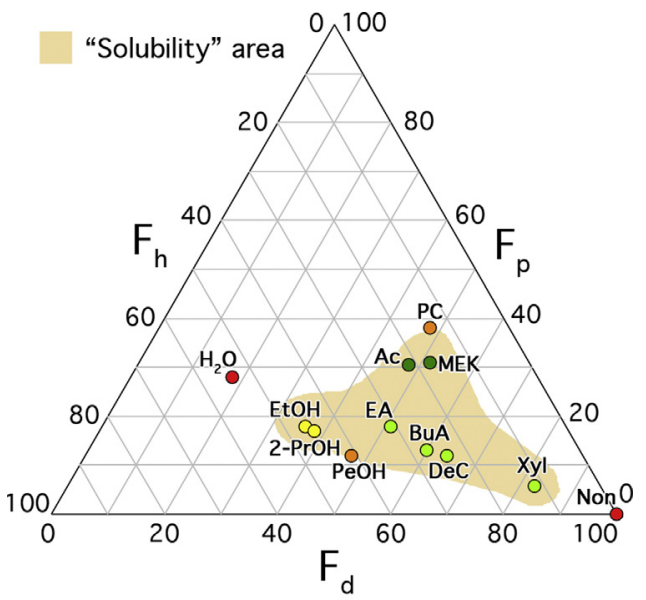

Easy removal

Removal with some mechanical action Partial removal with some mechanical action Poor removal

No removal

Fig. 3. Teas diagram showing the position and the average cleaning effectiveness of the tested solvents in the removal of the 17 selected spray-can paints. The brownish area represents the "solubility" region where solvents able to swell/soften and remove these classes of graffiti paints should fall, according to our cleaning tests results.

In general, relatively more polar solvents resulted to be the more effective and, in particular, ketones esters, xylene and diethyl carbonate were the solvents that, on average, proved to be the best in removing the spray-can paints from the glass slides. In Fig. 3 this was represented graphically, reporting the effectiveness of the tested solvents on a Teas graph. The average "solubility" area of the 17 spray-can paints was reported and superimposes to the one of most synthetic polymers commonly found in conservation of cultural heritage.

According to these results, two NSFs were formulated and selected to perform the same systematic set of cleaning tests on the 17 spray-can paint samples. 
Table 4

Cleaning tests with the two NSFs.

\begin{tabular}{|c|c|c|c|}
\hline Paint name & NSF A & NSF B & NSFs average results \\
\hline Malbec & 4 & 4 & 4.00 \\
\hline Bean brown & 4 & 4 & 4.00 \\
\hline Dioxazine purple light & 4 & 3 & 3.50 \\
\hline Flamingo & 4 & 4 & 4.00 \\
\hline Quinacridone rose & 1 & 3 & 2.00 \\
\hline Violeta vampiro & 3 & 4 & 3.50 \\
\hline Naphtol red & 4 & 4 & 4.00 \\
\hline Azul mahahual & 1 & 4 & 2.50 \\
\hline Naranja jaguar & 2 & 2 & 2.00 \\
\hline Azo orange light & 2 & 4 & 3.00 \\
\hline Rojo sacrificio & 3 & 4 & 3.50 \\
\hline Amarillo medio & 1 & 1 & 1.00 \\
\hline Magenta & 4 & 4 & 4.00 \\
\hline Blanco brillante & 1 & 1 & 1.00 \\
\hline Azul cielo & 2 & 2 & 2.00 \\
\hline Azul profundo & 2 & 2 & 2.00 \\
\hline Verde lima & 1 & 2 & 1.50 \\
\hline NSFs average results & 2.53 & 3.06 & \\
\hline
\end{tabular}

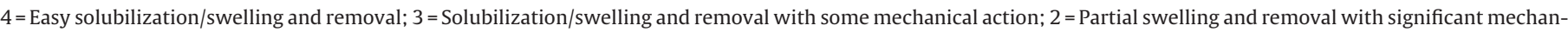
ical action; 1 = Partial swelling and poor removal; $0=$ No removal.

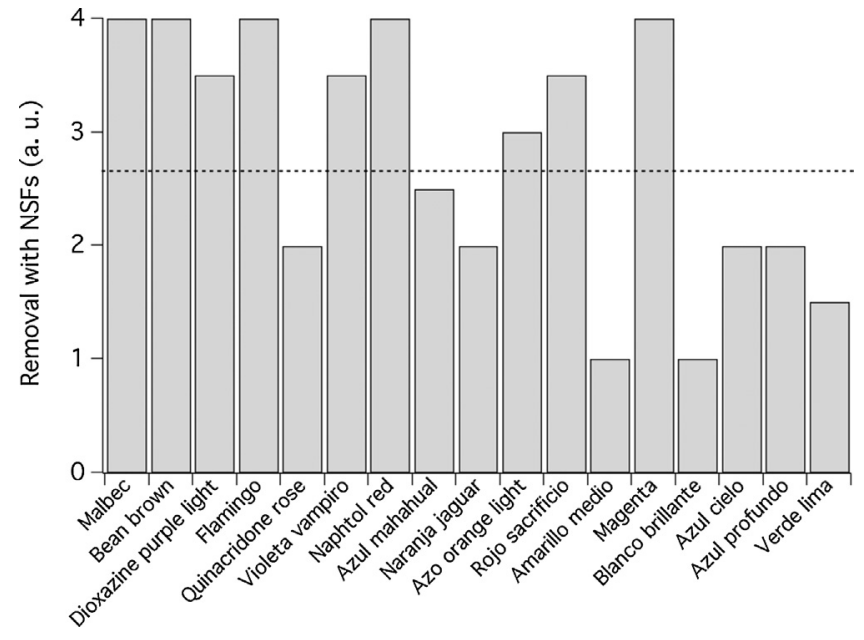

Fig. 4. This picture shows the average score of the cleaning tests performed with the two NSFs for each of the 17 spray-can paint samples. The dashed line is an eyeguide to help dividing the paints in two classes: easily-removable (above the line) and hardly-removable ones (below the line).

\subsection{Laboratory cleaning tests with NSFs}

The two NSFs chosen included, PeOH, PC and EA (NSF A) and 2-BuOH, PC, EA and MEK (NSF B), as the organic solvents, thus we expected that both systems could give good results in removing the paints from the glass support. Moreover, the two systems are differentiated by the nature of the surfactant, i.e. anionic in the case of NSF A and nonionic in the case of NSF B.

In Table 4, the complete results of the cleaning tests performed with the two NSFs are reported, together with the average results. Overall, both systems were able to effectively remove all the paints from the glass, even if, in some cases, some stronger mechanical action had to be used. System B resulted slightly, but significantly, more effective of system $A$, according to the average results on all the tested samples. This difference can be explained in view of two considerations: firstly, the NSF B has a higher content in organic solvents, which probably boosts its cleaning action; secondly, we recently observed that the $C_{9-11} E_{6}$ nonionic surfactant usually grants better cleaning performances than SDS, due to its ability to get very low interfacial tensions [34].
The values of last column of Table 4 are reported as histogram in Fig. 4, in order to get a clearer visual picture of the combined cleaning results of the two NSFs. A horizontal dashed line on the graph is an eye-guide, which should help in grouping the samples: the easily-removable (above the line) and the hardly-removable ones (below the line).

Similarly to what observed for the cleaning tests with neat solvents, and contrarily to what could be expected, this difference is not related to chemical nature of the paints' binder. Nonetheless, an interesting hypothesis can be formulated, by combining these results with the information reported in Table 2 . The last column of Table 2 shows that samples 5, 8, 9, 12, 14, 15, 16 and 17 (i.e. Quinacridone rose, Azul Mahahual, Naranja jaguar, Amarillo Medio, Blanco Brillante, Azul Cielo, Azul Profundo and Verde Lima) includes the following pigments or dyes: quinacridone, $\mathrm{Cu}-$ phtalocyanine, lead chromate $\left(\mathrm{PbCrO}_{4}\right)$, titanium dioxide $\left(\mathrm{TiO}_{2}\right)$ and prussian blue $\left(\mathrm{Fe}_{4}\left[\mathrm{Fe}(\mathrm{CN})_{6}\right]_{3} \cdot \mathrm{H}_{2} \mathrm{O}\right)$. Thus, with the sole exception of quinacridone (which is a synthetic organic pigment having a polycyclic molecular structure), all these paints are colored by the presence of mineral pigments or organometallic dyes, i.e. in all these paints transition metal ions are present: $\mathrm{Cu}(\mathrm{II}), \mathrm{Pb}(\mathrm{II}), \mathrm{Cr}(\mathrm{II})$, $\mathrm{Ti}(\mathrm{IV}), \mathrm{Fe}(\mathrm{II})$ and $\mathrm{Fe}(\mathrm{III})$. Moreover, it is worth noticing that the other paints (i.e. the easily-removable samples in Fig. 4) do not contain transition metal ions-based pigments or dyes. The correlation between the presence of such ions in the paints and their resistance to the action of solvents and NSFs was attributed to the catalytic action of metal ions with respect to cross-linking reactions of the paints' binders. In fact, as reported in Table 2, apart from sample 5 (polyurethane-based), the aforementioned more resistant paint samples are based on alkyd binders and it is known that such polymers behave as drying oils, i.e. undergo cross-linking reactions even several months after film formation. Our hypothesis is that when an alkyd-based paint contains pigments or organometallic dyes with transition metal ions, cross-linking reactions are catalyzed and the paint becomes less and less sensitive to the action of solvents upon ageing. This is in agreement with several published studies on the action of inorganic pigments and metal ions on the cross-linking of drying oils and alkyd resins [44-47]. On the other hand, this hypothesis does not fit the case of sample 5, where quinacridone is present as a dye. The reason for the resistance of the paint to the action of solvents is probably related to the formulation of the paint that includes some chemicals, whose synergistic action boosted the cross-linking of the polymeric binder, however not detected by ATR FT-IR analyses. 

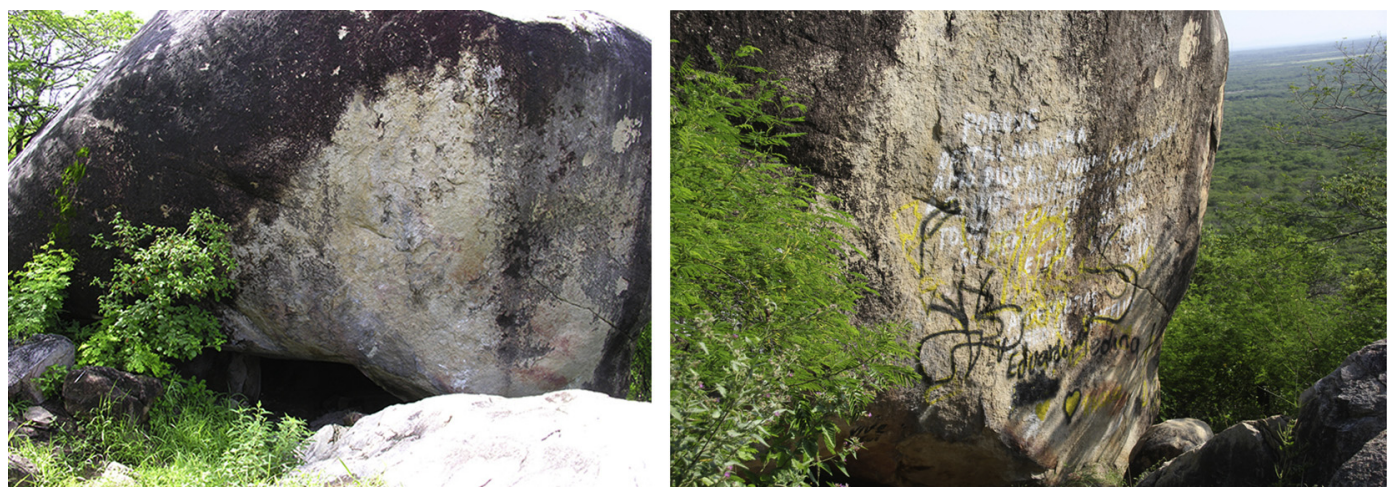

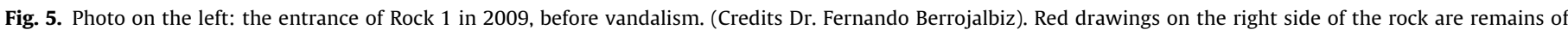
parietal art. Photo on the right: the entrance in 2016. (Credits Mitzi Vania García Toribio).
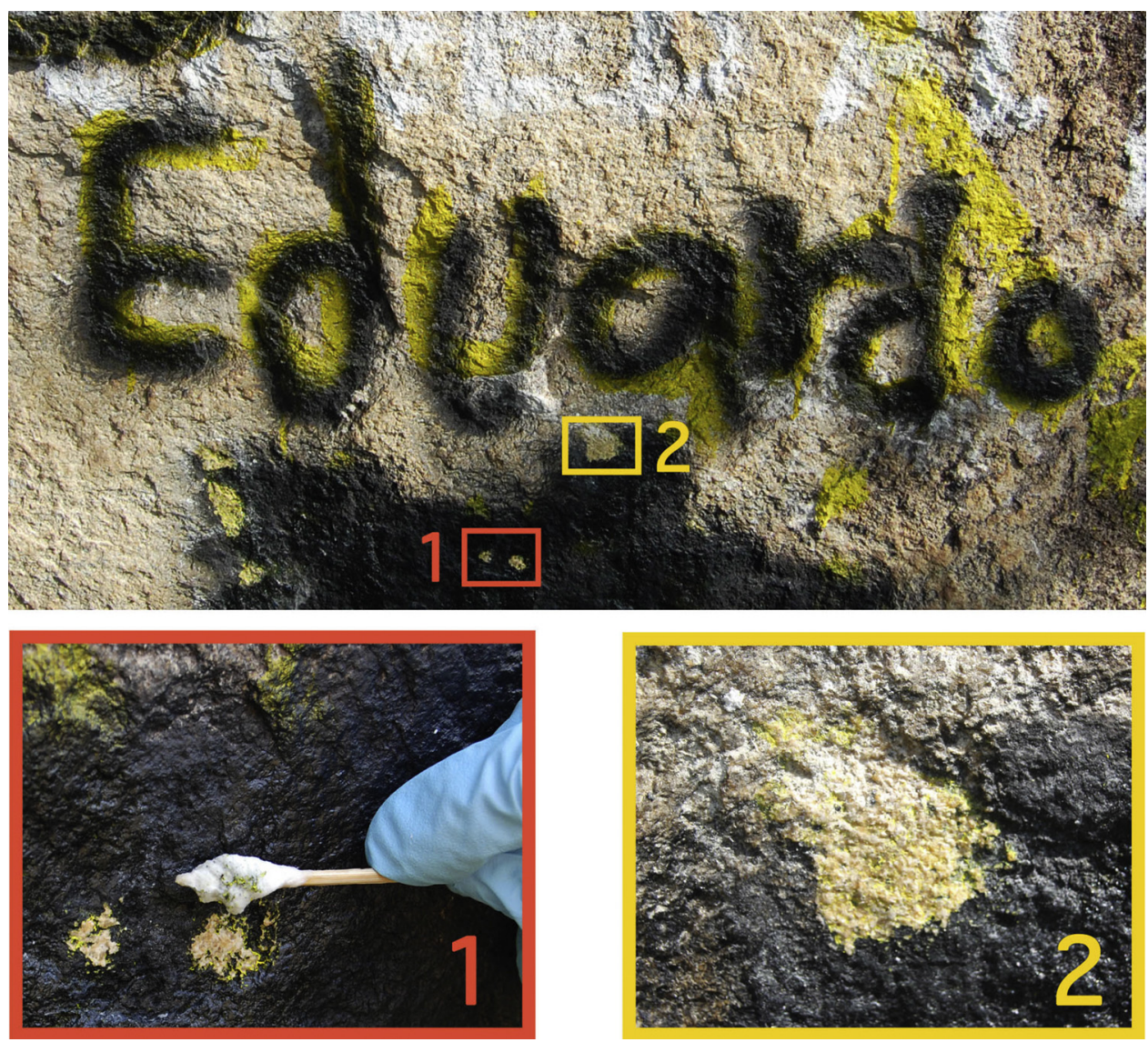

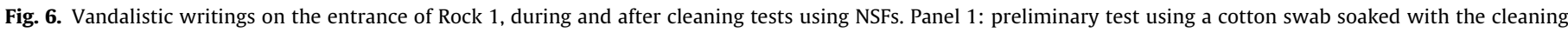

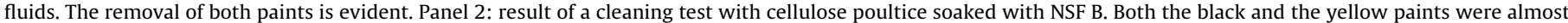
completely removed after one application.

\subsection{In situ graffiti removal}

Finally, NSFs A and B were tested in the removal of graffiti from archeological stones in Mexico. Ba' Cuana is an historical site located southwest of Cerro Blanco, in Asunción Ixtaltepec, on the isthmus of Tehuantepec. The site is composed of two rocks of monumental size facing southwest. On both rocks, several parietal paintings were drawn more than seven centuries ago. The rock shown in Fig. 5 is the nearest to the entrance of the site. Its lower face that forms a cave-like space with a very low ceiling is where the best-preserved original paintings can be found. As can be seen from Fig. 5, the stone has been vandalized in recent times and is now covered by drawings and writings on a face that includes remains of original paint.
Vandalistic drawings and signs were executed using white paint, yellow paint, and black spray paint. In several areas, these materials are superimposed. Lines and other undefined shapes are due to an oily black paint. NSFs A and B were tested to selectively remove the paints without altering the original drawings. Pictures in Fig. 6 show a detail of the right side of the rock, on which cleaning tests were carried out. Preliminary tests were performed using a cotton swab soaked with the cleaning fluid and rolled over the paint (Fig. 6-1). These tests were used to assess the efficacy of the NSFs on the selected paints. Following that, the cleaning of larger areas was carried out using cellulose poultices, soaked in the cleaning fluids. A plastic film was placed over the poultice to reduce the evaporation rate of the cleaning system during application. 
All the applicative tests carried out on the vandalistic graffiti of the Ba' Cuana site showed that system $\mathrm{A}$ is efficient in removing mainly the black paint, while system $B$ can be used for the removal of yellow and black paints from the rock in a single application (Fig. 6-2). Unfortunately, no characterization of the paints is available at present, thus neither the chemical nature of the binder, nor the nature of pigments/dyes is known about the graffiti paints of this archeological site. However, these tests are a clear example of the actual results achievable on real cases with NSFs. The main risk connected to the use of neat unconfined organic solvents in this case would have been the possible spreading of the black and yellow paints in the pores of the rocks, besides the threat of removing also the original red pigments due to the scarce control of the cleaning action.

\section{Conclusions}

Graffiti removal nowadays is a major task in conservation of cultural heritage, but traditional methods often present some limitations. Moreover, the great availability of different commercial materials used for graffiti further complicates the use of a well-aware scientific approach to their treatment and removal. Therefore, in the present work, a laboratory systematic survey on 17 spray-can paints commercially available in the Mexican area was carried out with the aim of giving a thorough characterization of a set of materials commonly used for graffiti and vandalism.

Then, cleaning tests were executed on the 17 paint samples using neat organic solvents (i.e. ketones, alcohols, esters, alkyl carbonates, aromatic hydrocarbons and alkanes) and two NSFs, which are water-based detergent systems. Both NSFs were effective in removing all the paints from the glass, with great advantages in terms of eco-friendliness and completeness of varnish removal.

Finally, as an example of a real conservation case, the proposed NSFs were tested in the removal of graffiti from archeological stones carrying pre-Hispanic paintings in the site of Ba' Cuana, Asunción Ixtaltepec, Oaxaca, Mexico. It is worth noting that in real cases graffiti removal is a very complex issue, due to the great number of variables at play: ageing of the paint, weathering, chemical nature, roughness and porosity of the substrate, presence of original paintings to be preserved (as in the present case), and so on. However, both cleaning systems tested were shown to be effective for the selective and controlled graffiti removal, proving that NSFs are a growingly established and convenient alternative to the use of neat unconfined organic solvents in cleaning of cultural heritage.

\section{Acknowledgements}

CSGI is acknowledged for partly funding this work, which was otherwise supported by the European Union (CORDIS) - Project NANORESTART (H2020-NMP-21-2014/646063). Project "Investigación y prevención del graffiti en el patrimonio cultural in situ" CNCPC-ENCRyM- INAH and Centro INAH Oaxaca are also acknowledged.

\section{References}

[1] R. Giorgi, M. Baglioni, P. Baglioni, Nanofluids and chemical highly retentive hydrogels for controlled and selective removal of overpaintings and undesired graffiti from street art, Anal. Bioanal. Chem. (2017) 1-6, http://dx.doi.org/10.1007/s00216-017-0357-z.

[2] N. Careddu, O. Akkoyun, An investigation on the efficiency of waterjet technology for graffiti cleaning, J. Cult. Herit. 19 (2016) 426-434, http://dx.doi.org/10.1016/j.culher.2015.11.009.

[3] V.E. Selva Bonino, Dall'olio all'acrilico, dall'impressionismo all'arte contemporanea: studi, ricerche, indagini scientifiche ed interventi conservativi: Atti del congresso Milano 13-14 novembre 2015, VII congresso internazionale Colore e Conservazione, Il Prato, Saonara, 2016.
[4] P. Sanmartín, F. Cappitelli, R. Mitchell, Current methods of graffiti removal: a review, Constr. Build. Mater. 71 (2014) 363-374, http://dx.doi. org/10.1016/j.conbuildmat.2014.08.093.

[5] M.J. Whitford, Getting Rid of Graffiti: A Practical Guide to Graffiti Removal and Anti-graffiti Protection, Taylor \& Francis, 1992.

[6] J.S. Pozo-Antonio, A. Ramil, M.P. Fiorucci, A.J. López, T. Rivas, The use of hyperspectral imaging technique to detect the most suitable graffiti-cleaning procedure, Color Res. Appl. 41 (2016) 308-312, http://dx.doi.org/10.1002/col 22032.

[7] S. Samolik, M. Walczak, M. Plotek, A. Sarzynski, I. Pluska, J. Marczak, Investigation into the removal of graffiti on mineral supports: comparison of nano-second Nd:YAG laser cleaning with traditional mechanical and chemical methods, Stud. Conserv. 60 (2015) S58-S64, http://dx.doi.org/10.1179/0039363015Z.000000000208.

[8] S. Chapman, Laser technology for graffiti removal, J. Cult. Herit. 1, Supplement 1 (2000) S75-S78, http://dx.doi.org/10.1016/S1296-2074(00)00153-9.

[9] J.S. Pozo-Antonio, T. Rivas, M.P. Fiorucci, A.J. López, A. Ramil, Effectiveness and harmfulness evaluation of graffiti cleaning by mechanical, chemical and laser procedures on granite, Microchem. J. 125 (2016) 1-9, http://dx.doi.org/10.1016/j.microc.2015.10.040.

[10] M. Carvalhão, A. Dionísio, Evaluation of mechanical soft-abrasive blasting and chemical cleaning methods on alkyd-paint graffiti made on calcareous stones, J. Cult. Herit. 16 (2015) 579-590, http://dx.doi.org/10.1016/j.culher.2014.10.004.

[11] M. Licchelli, S.J. Marzolla, A. Poggi, C. Zanchi, Crosslinked fluorinated polyurethanes for the protection of stone surfaces from graffiti, J. Cult. Herit. 12 (2011) 34-43, http://dx.doi.org/10.1016/j.culher.2010.07.002.

[12] O. García, K. Malaga, Definition of the procedure to determine the suitability and durability of an anti-graffiti product for application on cultural heritage porous materials, J. Cult. Herit. 13 (2012) 77-82, http://dx.doi.org/10.1016/j.culher.2011.07.004.

[13] S. Goidanich, L. Toniolo, S. Jafarzadeh, I.O. Wallinder, Effects of waxbased anti-graffiti on copper patina composition and dissolution during four years of outdoor urban exposure, J. Cult. Herit. 11 (2010) 288-296, http://dx.doi.org/10.1016/j.culher.2010.02.001.

[14] M. Lettieri, M. Masieri, Surface characterization and effectiveness evaluation of anti-graffiti coatings on highly porous stone materials, Appl. Surf. Sci. 288 (2014) 466-477, http://dx.doi.org/10.1016/j.apsusc.2013.10.056.

[15] P. Ortiz, V. Antúnez, R. Ortiz, J.M. Martín, M.A. Gómez, A.R. Hortal, B. Martínez-Haya, Comparative study of pulsed laser cleaning applied to weathered marble surfaces, Appl. Surf. Sci. 283 (2013) 193-201, http://dx.doi.org/10.1016/j.apsusc.2013.06.081.

[16] F. Brygo, C. Dutouquet, F. Le Guern, R. Oltra, A. Semerok, J.M. Weulersse, Laser fluence, repetition rate and pulse duration effects on paint ablation, Appl. Surf. Sci. 252 (2006) 2131-2138, http://dx.doi.org/10.1016/j.apsusc.2005.02.143.

[17] A. Costela, I. García-Moreno, C. Gómez, O. Caballero, R. Sastre, Cleaning graffitis on urban buildings by use of second and third harmonic wavelength of a Nd:YAG laser: a comparative study, Appl. Surf. Sci. 207 (2003) 86-99, http://dx.doi.org/10.1016/S0169-4332(02)01241-2.

[18] C. Gómez, A. Costela, I. García-Moreno, R. Sastre, Comparative study between IR and UV laser radiation applied to the removal of graffitis on urban buildings, Appl. Surf. Sci. 252 (2006) 2782-2793, http://dx.doi.org/ 10.1016/j.apsusc.2005.04.051.

[19] J. Penide, F. Quintero, A. Riveiro, A. Sánchez-Castillo, R. Comesaña, V. del Keeping historical with lasers. How to remove the graffiti without damaging the underlying material. (Application report), Ind Laser Solut. (2013) 18-21.

[20] T. Rivas, S. Pozo, M.P. Fiorucci, A.J. López, A. Ramil, Nd:YVO4 laser removal of graffiti from granite. Influence of paint and rock properties on cleaning efficacy, Appl. Surf. Sci. 263 (2012) 563-572, http://dx.doi.org 10.1016/j.apsusc.2012.09.110.

[21] G. Ranalli, M. Matteini, I. Tosini, E. Zanardini, C. Sorlini, Bioremediation of cultural heritage: removal of sulphates, nitrates and organic substances, in: 0 . Ciferri, P. Tiano, G. Mastromei (Eds.), Microbes Art, Springer, US, 2000, pp. 231-245, http://dx.doi.org/10.1007/978-1-4615-4239-1_16.

[22] G. Ranalli, C. Belli, G. Alfano, G. Lustrato, E. Zanardini, F. Cappitelli, C. Sorlini, Bio-cleaning of cultural heritage surfaces: biotechnological contributions. Bioremediation of works of art, Househ. Pers. Care Today 3 (2009) 36-39.

[23] A. Webster, E. May, Bioremediation of weathered-building stone surfaces, Trends Biotechnol. 24 (2006) 255-260, http://dx.doi.org/10.1016/j. tibtech.2006.04.005.

[24] F. Troiano, S. Vicini, E. Gioventù, P.F. Lorenzi, C.M. Improta, F. Cappitelli, A methodology to select bacteria able to remove synthetic polymers, Polym. Degrad. Stab. 107 (2014) 321-327, http://dx.doi.org/10.1016/j. polymdegradstab.2013.12.029.

[25] L. Borgioli, G. Caminati, G. Gabrielli, E. Ferroni, Removal of hydrophobic impurities from pictorial surfaces by means of heterogeneous systems, Sci. Technol. Cult. Herit. J. Of. 4 (1995) 67-74.

[26] E. Carretti, L. Dei, C. Miliani, P. Baglioni, Oil-in-water microemulsions to solubilize acrylic copolymers: application in cultural heritage conservation, in: P.P.G. Koutsoukos (Ed.), Trends Colloid Interface Sci. XV, Springer, Berlin Heidelberg, 2001, pp. 63-67 (accessed July 10, 2014) http://link.springer.com/chapter/10.1007/3-540-45725-9_14.

[27] E. Carretti, L. Dei, P. Baglioni, Solubilization of acrylic and vinyl polymers in nanocontainer solutions. Application of microemulsions and micelles to cultural heritage conservation, Langmuir. 19 (2003) 7867-7872, http://dx.doi.org/10.1021/la034757q. 
[28] M. Baglioni, R. Giorgi, D. Berti, P. Baglioni, Smart cleaning of cultural heritage: a new challenge for soft nanoscience, Nanoscale. 4 (2012) 42, http://dx.doi.org/10.1039/c1nr10911a.

[29] M. Baglioni, M. Raudino, D. Berti, U. Keiderling, R. Bordes, K. Holmberg, P. Baglioni, Nanostructured fluids from degradable nonionic surfactants for the cleaning of works of art from polymer contaminants, Soft Matter. 10 (2014) 6798-6809, http://dx.doi.org/10.1039/C4SM01084A.

[30] M. Baglioni, Y. Jáidar Benavides, A. Desprat-Drapela, R. Giorgi, Amphiphilebased nanofludis for the removal of styrene/acrylate coatings: Cleaning of stucco decoration in the Uaxactun archeological site (Guatemala), J. Cult. Herit. 16 (2015) 862-868, http://dx.doi.org/10.1016/j.culher.2015.03.008.

[31] M. Baglioni, Y. Jàidar Benavides, D. Berti, R. Giorgi, U. Keiderling, P. Baglioni, An amine-oxide surfactant-based microemulsion for the cleaning of works of art, J. Colloid Interface Sci. 440 (2015) 204-210, http://dx.doi.org/10.1016/j.jcis.2014.10.003.

[32] M. Baglioni, D. Rengstl, D. Berti, M. Bonini, R. Giorgi, P. Baglioni, Removal of acrylic coatings from works of art by means of nanofluids: understanding the mechanism at the nanoscale, Nanoscale. 2 (2010) 1723, http://dx.doi.org/10.1039/c0nr00255k.

[33] M. Raudino, G. Selvolini, C. Montis, M. Baglioni, M. Bonini, D. Berti, P. Baglioni, Polymer films removed from solid surfaces by nanostructured fluids: microscopic mechanism and implications for the conservation of cultural heritage, ACS Appl. Mater. Interf. 7 (2015) 6244-6253, http://dx.doi.org/10.1021/acsami.5b00534.

[34] M. Baglioni, C. Montis, F. Brandi, T. Guaragnone, I. Meazzini, P. Baglioni, D. Berti, Dewetting acrylic polymer films with water/propylene carbonate/surfactant mixtures-implications for cultural heritage conservation, Phys. Chem. Chem. Phys. (2017), http://dx.doi.org/10.1039/C7CP02608K.

[35] M.T. Doménech-Carbó, A. Doménech-Carbó, J.V. Gimeno-Adelantado, F. BoschReig, Identification of synthetic resins used in works of art by Fourier Transform infrared spectroscopy, Appl. Spectrosc. 55 (2001) 1590-1602, http://dx.doi.org/10.1366/0003702011954152.

[36] F. Govaert, M. Bernard, Discriminating red spray paints by optical microscopy, Fourier transform infrared spectroscopy and X-ray fluorescence, Forensic Sci. Int. 140 (2004) 61-70, http://dx.doi.org/10.1016/j.forsciint.2003.11.015.
[37] R. Ploeger, D. Scalarone, O. Chiantore, The characterization of commercial artists' alkyd paints, J. Cult. Herit. 9 (2008) 412-419, http://dx.doi.org/10.1016/j.culher.2008.01.007.

[38] D. Rosu, L. Rosu, C.N. Cascaval, IR-change and yellowing of polyurethane as a result of UV irradiation, Polym. Degrad. Stab. 94 (2009) 591-596, http://dx.doi.org/10.1016/j.polymdegradstab.2009.01.013.

[39] C. Defeyt, J. Langenbacher, R. Rivenc, Polyurethane coatings used in twentieth century outdoor painted sculptures. Part I: comparative study of various systems by means of ATR-FTIR spectroscopy, Herit. Sci. 5 (2017), http://dx.doi.org/10.1186/s40494-017-0124-7.

[40] T. Learner, Getty Conservation Institute, Eds., Modern paints uncovered: proceedings from the modern paints uncovered symposium, Getty Conservation Institute, Los Angeles, 2007.

[41] D.O. Hummel, Atlas of Plastics Additives, Springer, Berlin Heidelberg, Berlin, Heidelberg, 2002, http://dx.doi.org/10.1007/978-3-642-56211-2.

[42] X. Sun, V. Duffort, L.F. Nazar, Prussian blue Mg-Li hybrid batteries, Adv. Sci. 3 (2016) 1600044, http://dx.doi.org/10.1002/advs.201600044.

[43] S.Q. Lomax, M.R. Schilling, T.J.S. Learner, The identification of synthetic organic pigments by FTIR and DTMS, in: Mod. Paints Uncovered Proc. Mod. Paints Uncovered Symp., 2007, pp. 105-117.

[44] R. Vangorkum, E. Bouwman, The oxidative drying of alkyd paint catalysed by metal complexes, Coord. Chem. Rev. 249 (2005) 1709-1728, http://dx.doi.org/10.1016/j.ccr.2005.02.002.

[45] V. Št'áva, D. Veselý, P. Kalenda, Catalytic effects of transition metals in the form of the salts of organic acids in the cross linking of alkyds, Pigment Resin Technol. 37 (2008) 67-72, http://dx.doi.org/10.1108/03699420810860400.

[46] R. Hage, J. de Boer, K. Maaijen, Manganese and iron catalysts in alkyd paints and coatings, Inorganics. 4 (2016) 11, http://dx.doi.org/10. 3390/inorganics4020011.

[47] F.N. Jones, M.E. Nichols, S.P. Pappas, Organic Coatings: Science and Technology, John Wiley \& Sons, 2017 